\title{
Tangible interaction in museums and temporary exhibitions: embedding and embodying the intangible values of cultural heritage
}

\author{
Duranti, Daniele $^{a}$; Spallazzo, Davide ${ }^{\text {b }}$; Trocchianesi, Raffaella ${ }^{c}$. \\ ${ }^{a} \mathrm{PhD}$ candidate, IMT School for Advanced Studies, Lucca, Italy. daniele.duranti@imtlucca.it. \\ ${ }^{\mathrm{b}}$ Post-doc research fellow, Dipartamento di Design, Politecnico di Milano, Italy. davide.spallazzo@polimi.it. \\ ${ }^{c}$ Associate Professor, Dipartamento di Design, Politecnico di Milano, Italy. raffaella.trocchianesi@polimi.it.
}

\begin{abstract}
Moving from a design perspective, the paper explores the potential of tangible interaction in giving shape to intangible contents in museums and temporary exhibitions.

Going beyond tangibility intended in the strict sense of touching assets we use here a wider interpretation of tangibility that considers touch in the sense of embodied experience. In this way we consider as tangible all those experiences that foster a strong involvement of the body when interacting with digital content. This includes objects-based and gesturesbased interactions.

Tangible interaction is interpreted as a practice able to multiply the levels of the narrative, to make the visit experience memorable and to give materiality to intangible values. This approach uses tangible interaction as a way to let the audience experience practices and rituals linked to the contents and representative of the intangible values embedded in the assets.
\end{abstract}

The potential of tangible interaction to foster the intangible values of cultural heritage is discussed starting from a provisional classification of tangible interaction case studies. In particular four different categories are identified that are: smart replicas/originals, symbolic objects, codified gestures and performing gestures.

In conclusion, two possible design strategies that employ tangible interaction for enabling the experience of intangible values of cultural heritage are highlighted. These are:

Embedding meaning: it consists in creating sensorised objects that embed in themselves meanings related to intangible values of cultural heritage, and that communicate explicitly this meaning in their physicality;

Embodying meaning: it consists in integrating a meaning related to intangible values in gestures, so that intangible values are communicated implicitly in the action performed by the visitor.

Keywords: tangible interaction, intangible values, design-driven approach, cultural heritage, exhibit design. 
Tangible interaction in museums and temporary exhibitions: embedding and embodying the intagible values of cultural heritage.

\section{Introduction}

The application of interactive technologies to museums and temporary exhibitions has been for long time a topic of research in Interaction Design, Human-Computer Interaction (HCI) and related disciplines. One of the last trends in the field has regarded the research of technological solutions that allow for a fuller integration between the technology, the materiality of the objects and the physicality of the visit experience (Bannon et al., 2005; Petrelli et al., 2013). The importance of the physical engagement with heritage has been also highlighted by various works in museum studies (Chatterje, 2008; Pye, 2008; Dudley, 2011). This had led to the design of mixed reality installations that make use of technologies like augmented reality (e.g. Vlahakis et al., 2002), augmented virtuality (e.g. Hall et al., 2001) and tangible and embodied interaction (e.g. Rawat et al., 2005; Taylor et al., 2015) with the purpose of designing technologies that are better integrated with the real physical world and that require interactions similar to those people carry out in the real world.

This paper focuses on tangible and embodied interactive systems. Going beyond tangibility intended in the strict sense of touching assets, we use here the wider interpretation of tangibility as it has come to be considered today in the technological world (Hornecker et al., 2006). This interpretation considers as tangible all those experiences that require a strong involvement of the body when interacting with a digital system. Indeed, in tangible interaction systems the visitors interact by manipulating tangible objects or by making actions through gestures or the whole body.

In particular this paper aims to explore a peculiar aspect of tangible interaction, that is, its potential in giving physical shape to the intangible values of cultural heritage. First, the concepts of tangible and embodied interaction will be illustrated along with an overview of related works in the cultural heritage field. In order to lay the groundwork for the discussion of our research, the concept of intangible values and how it has been used in the exhibit design practice will be described. Then, a provisional categorization of different tangible interaction systems will be presented and used as a starting point to investigate and discuss the ability of tangible interaction to foster intangible values of cultural heritage. To conclude, different design strategies that make use of tangible interaction as a means to foster intangible values in cultural heritate will be highlighted and explained.

\section{Tangible interaction, Embodied experience: definitions and related works in $\mathbf{C H}$}

Tangible interaction is a field of research inside HCI and Interaction design. Research in this field is part of a trend that became prominent in the mid 90s aiming to overcome the limits of desktop computers and virtual reality, particularly the fact that they estrange people from the real world (Shaer et al., 2010). A firm belief emerged at that time that instead of enclosing people in a virtual world, effective technical solutions should be developed to integrate digital functionalities directly in the real world (Wellner et al., 1993).

Technologies that integrate the digital and real world are globally referred to as mixed reality (Milgram et al., 1994; Coutrix et al., 2006). Augmented reality and augmented virtuality systems are examples of technologies that allow for an integration between the two dimensions - real and virtual - from a visual point of view. In the former, the real environment is augmented by overlapping digital information to it, while in the latter, direct representations of reality are inserted into virtual reality environments.

Tangible interaction emerged as a way to allow for an integration also at the level of the interaction (Ishii et al., 1997). Different disciplines have contributed to what is now known as tangible interaction, namely Computing and HCI, Product and Industrial Design and Arts. For this reason the expression tangible 
interaction has come to be considered today as an umbrella term encompassing "a broad range of different systems and interfaces relying on embodied interaction, tangible manipulation and physical representation (of data), embeddedness in real space and digitally augmented physical spaces" (Hornecker et al. 2006, p. 437). In other words, tangible interaction systems propose a kind of interaction with digital systems that is similar to the way people interact in the physical world, that is, through specific physical objects or through gestures and full-body movements, and not using generic devices like the mouse, the keyboard or the joystick. It is important to point out that the expression embodied interaction is sometimes used by some authors in place of tangible interaction especially when referring to the wholebody or gesture interaction (Hornecker). This expression has become popular in Human Computer Interaction after the publication of the book Where the action is (Dourish, 2001). A recent overview on the application of the notion of embodiment to HCI is provided by Marshall et al. (2013).

Mixed reality technologies have become a topic of research also in the cultural heritage field (Bannon et al., 2005) because of their potential of overcoming one of the issues regarding the application of technologies to museums and exhibitions, that is, the distraction and disengagement of visitors from the real objects and their materiality (Ciolfi, 2003; Vom Lehm et al., 2003; Stevens, 2004). Therefore, augmented reality systems started to be employed in the cultural heritage field for their ability to overlap digital information directly on the objects on display (e.g. Vlahakis et al. 2002;). Similarly, augmented virtuality systems were developed to augment virtual environments with a representation of real objects (Hall et al., 2001). In parallel with an increasing interest in the materiality of the visit experience shown in museum studies (Chatterje, 2008; Pye, 2008; Dudley, 2011), also tangible and embodied interaction systems have been applied to museums and exhibitions in their different forms. These include technological systems like tangible tabletops (Hsieh et al., 2010), smart objects (Rawat et. al, 2005), and smart physical places (Ciolfi et al., 2005). Although different in forms, all these systems require similar interaction styles: through the manipulation of specific tangible objects (object-based interaction) or through free gestures (gestures-based interaction).

Pioneering research in the field of tangible interaction applied to cultural heritage started in the early 2000s with the European SHAPE (Situating Hybrid Assemblies in Public Environment) project (Bannon et al., 2005). SHAPE aimed to develop assemblies of hybrid, mixed reality artefacts in public spaces like museums and exploratoria and to examine the behaviours of visitors in relation to them. Two public exhibitions were developed and tested through visitor studies and some guidelines for the design of similar experiences were discussed (Fraser et al., 2003; Ferris et al., 2004; Ciolfi et al., 2005).

The still on-going European meSch projects (Material EncounterS with digital Cultural Heritage) is also dealing with tangible interaction (Petrelli et al., 2013). Started in 2013, its main goal is exploring new prototypes of tangible interaction (e.g. Petrelli et al., 2014) with the aim of bridging the gap between heritage and digital content, and also creating a platform that allows cultural heritage professionals to design, make and maintain interactive artefacts. Many reflections about the application of co-design methodologies in museums have also emerged as part of meSch (Ciolfi et al., 2016). Besides the two European projects, other tangible interaction systems have emerged both from research and museum practice, so that today the field is characterized by a strong variety.

What emerges from this overview is that so far the research in the field has been mainly practical and focused on the design and evaluation of new interactive systems, while not many theoretical works have been developed. With the aim of overcoming at least partially this gap one of the authors of this paper is currently developing a $\mathrm{PhD}$ research. As part of this on-going research, many projects that make use of tangible interaction in the cultural heritage field have been collected for analysis. The collection includes 
Tangible interaction in museums and temporary exhibitions: embedding and embodying the intagible values of cultural heritage.

both projects coming from research activities and design practice. The case studies that will be presented and discussed in this paper represent a subset of this collection.

\section{Intangible values of Cultural Heritage in the exhibit design practice}

The value of the cultural heritage is not only related to the connotative features of a specific cultural asset (such as the authenticity, the rarity, the preciousness, the manufacture, the prestige of the artist...) but also to its intangible significance (such as the circumstances of its realization, the stratification of its belonging to different owners, its symbolic and archetypal identity, its being object of traditions or oral narratives ...). This latest aspect - the intangible value - can be made evident by some of the strategies typical of the exhibit design practice. In this paper tangible interaction is interpreted as a practice able to multiply the levels of the narrative, to make the visit experience memorable and to give materiality to intangible values. This approach uses tangible interaction as a way to let the audience experience practices and rituals linked to the contents and representative of the intangible values embedded in the assets. Therefore we can identify "gesture-through" and "object-through" interactions able to enhance the visitor experience and the understanding of cultural heritage. In this context the word "mediation" represents a crucial point because it means the potential of the expository artefacts and the technological devices in multiplying the narrative of the cultural asset. Putnam - in his book Museum as medium (2009) pinpoints some models of museums (such as Wunderkammer, Open Archive, Creator-Curator...) aimed at representing the tangible and intangible value of collections. The crucial concept that he suggests is: "replacing the value". This approach takes into account the potential of the displacement in stressing the relationship between the tangible and the intangible value of the cultural asset exhibited. "All museums through their chosen mode of displaying, using the traditional devices of plinth, vitrine and label, have the potential to transform almost anything they exhibit into a work of art." (Putnam, 2009, p. 36). On the one hand, this way of showing artefacts takes advantage of the traditional display (vitrine) in order to reinterpret the meaning, but on the other hand vitrines are the most "celebratory" expository elements that do not allow a tangible interaction with the object. Therefore this use of them is interesting because it opens to different interpretations of the perception of the cultural object and the potential to transmit its intangible value. "The vitrine reinforces the notion of the unique, untouchable and unattainable and, perhaps significantly, has its roots in the medieval church reliquary. It therefore enhances the inherent visual power of an object to catch a viewer's attention and to stimulate contemplation. The effect of placing something in a vitrine is to "museumize" it: the glass scates not just a physical barrier but establishes an "official distance" between object and viewer." (ivi). In this essay we are challenging this distance in support of a "dynamic" interface able to activate various narratives around the object exhibited.

In this perspective we can mention the installation Object de Guerre 1-4 (2000-2006) by the young artist Joreige who focuses her works on testimonies about the war in Lebanon. She asked to each person involved to choose an object meaningful for his daily life or for its symbolic value in order to trigger the narrative about his experience. The result is a plural photograph that aims at portraying a plethora of points of view around a unique and intense topic: the memory of the war. The exhibit consists both of real objects exhibited in vitrines with label that mentions the owner's name and his video-testimony; this last one becomes active when visitors get close to the vitrines. The combination of the multimedia language and the "traditional" expository element (vitrine) appears as a contrast: on the one hand the videotestimony gets close visitors to the witness because it stages his way of speaking and his way of narrating himself through the object like a "public intimacy"; on the other hand, the vitrine isolates the object in order to celebrate, decontextualize and offer it to the glance of visitors away from its physical and emotional habitat. 
The mediation between object and visitors and between object and space is an important topic able to reflect the communicative and narrative vocation of the object exhibited. Designing the cultural experience means indeed designing the relationship between visitor and cultural asset.

The concept of the "object-through" mentioned before is perceptible and understandable thanks to new communication registers and new media-relational requirements of daily objects. The Whispering Table installation (TheGreenEyl for the Jewish Museum in Berlin, 2009) use the "chance" of the object - an object with a high gradient of ritual such as one present in a set decked table - in order to cope with the topic of the religion by means of food and objects around it. The space is almost dark equipped with black tables on which white, lighted kitchen objects stand out. Visitors can seat down around the table, take the objects and get them close to their ears: the objects reveal some sound narratives telling the symbolic meaning of food, rituals and religious belief. The objects communicate also among them: according to their disposition on the table, they tell stories about differences and similarities among cultures. The visitor arranges the things and listens to the stories like an actor of a renewed ritual. The memory of the bodily movements in the space allows to sediment knowledge in a permanent way.

In both the examples mentioned before, the tangible interaction moves the visitor's attention from the objects exposed to their intangible value. The intangible dimension triggers three levels of cultural experience: the memory, the stratification of contents and the emotive engagement.

Tangible interaction can act as a vehicle in fostering the attention and incentive towards an emotional cultural experience. The use of multimedia and interactive technologies can generate a sort of "virtuous destabilization" that stages a new concept of diffuse performativity. As designers that give shape to the relationship between visitors and the cultural asset we have to consider a crucial issue: the risk of the excess of the semiotic saturation in the communicative interface. Therefore in designing this "mediation" we have to consider that new technologies foster the dematerialization of exhibit systems and objects (Balzola and Rosa 2011). Both interaction and interactivity are key points in designing cultural experiences: according to Balzola and Rosa (ibidem) on the one hand interaction is a direct relational form among two entities or more that communicate to each other and that transfer emotions, narratives and other information in a specific moment; on the other hand interactivity is an intercepted interaction because the process of the relation is recorded by a digital device.

In this perspective we are moving towards an aesthetics based on behaviours and not only on shapes. For this reason, the effect of the device interface through which we interact with the cultural asset is such important as the consistency of the interface itself. Sometimes if the interfaces are "natural", the audience engagement is immediate. Actions, natural for humans, like blowing, shouting, clapping, touching can become means to trigger contents in a meaningful and, at the same time, simple way.

\section{Investigating the ability of tangible interaction as a means to foster intangible values of $\mathrm{CH}$ : a provisional categorization}

Manipulating, touching, moving, rising as well as other bodily gestures are becoming common means of activating and controlling digital interpretations of the artworks as well as actions aimed to elicit the intangible values the assets bear with them.

Analysing these novel ways of interacting with cultural assets, it emerges a clear distinction between those experiences that prompt visitors to touch objects and those that rely on bodily movements without physical contact. This distinction is commonly identified in the field of Interaction Design with the two terms embedded interaction and embodied interaction, referring the first to the incorporation of sensing 
Tangible interaction in museums and temporary exhibitions: embedding and embodying the intagible values of cultural heritage.

and computational capabilities within objects and the second to the ability of systems of reading and interpreting gestures and full-body movements.

Translating embedded interaction in $\mathrm{CH}$ field means enabling an object-through interaction, being the object a smart copy of the artwork in exhibit, an object imbued with symbolic meaning or a simple smart object with no reference to the assets. The manipulation is the major means of interaction with the objects that, according to what visitors do with it, activate digital interpretations.

On the other side, systems based on embodied interaction enable a gesture-through interaction, using the human body as controller of the digital world. By reading gestures or full-body movements the digital system can modify accordingly, being the gestures simple movements of a hand, codified gestures (e.g. recreating in the air those we usually do with fingers on a touch screen) or articulated movements involving all the body.

As already stated, the aim of this study is to analyse the potential of tangible interaction in eliciting the intangible values of cultural assets. That said, the simple distinction between embedded and embodied interaction seems weak in describing the relevance of the objects/gestures in relation to the values the interaction elicits. Therefore, we propose four categories for grouping experiences of tangible interaction, here listed and described in the following: (1) smart replicas/originals, (2) symbolic objects, (3) codified gestures and (4) performing gestures, being the first two mostly related to embedded interaction and the last to embodied interaction.

\subsection{Smart replicas/originals}

The category smart replicas/originals collects those experiences based upon technology-enhanced objects. These objects can be:

- smart replicas, that are copy of artworks on show, usually realized through digital manufacturing, that embed sensors;

- smart originals, that are original artworks and assets enhanced with digital technology and sensing capabilities.

What these categories share is a direct and easily understandable relation between the technologyenhanced objects and the artworks they are augmenting and interpreting and the possibility to touch and handle objects.

In the case of smart replicas, by manipulating real-size or scaled reproduction of artworks embedded with buttons and sensors visitors can (1) activate and control digital contents and eventually (2) experience sensorial aspects of the object such as the superficial finishing.

The copies of the untouchable original artworks are usually obtained acquiring digitally the shape of the original (typically through laser scanning or photogrammetry), modifying it in order to host sensors and controllers and then reproducing it in the most appropriate scale with 3D printers or milling machines.

An example in this sense is provided by the VIRTEX presentation method, by Daniel Pletinckx, firstly proposed at the Archaeological Museum Ename in Belgium in 2007 and then integrated in the Keys to Rome exhibition at the Allard Pierson Museum of Amsterdam in 2014. The first example consists of a bigger replica of a small ivory cross embedded with a gyroscope that allows users to move a 3D model by actually moving the replica, and buttons - recognisable as black dots - that trigger video contributions when activated. The same interaction model is proposed in the Keys to Rome exhibition that exposes two "sensorised" replicas of the Ara Pacis and of the Augusto of Prima Porta, whose originals are both in 
Rome. The two monuments are proposed in a small scale in order to allow visitors to manipulate them, and set near to a plaster copy of a bass relief (Ara Pacis) and of the statue (Augusto of Prima Porta).

Smart originals, as the name suggests, propose the same interaction model but instead of using replicas, the real artworks and assets are embedded with sensors. A relevant example in the field is provided by the temporary exhibition Fragments of memory (Frammenti di memoria) by Gabriel Rapetti, that uses smart originals related to the farming. By touching the objects of the exhibition visitors can start light effects and activate stories of farmers told by the objects that evoke the atmosphere of past times in a whimsical way.

\subsection{Symbolic objects}

Interacting with the original artworks or with their copy is not the unique way of allowing visitors to handle smart objects and gain interpretation: smart objects can indeed be somehow related to the exhibit without having a strict formal relation with the assets on show.

We categorise these experiences as symbolic objects, since we include those projects that employ smart objects, icons or elements imbued with symbolic meaning as a vehicle to reach the intangible value of the cultural asset. In other words, the smart object itself, beyond its capability of activating contents on manipulation, becomes symbolic in itself by means of its shape and evocative power.

The exhibition The Hague and the Atlantic Wall: War in the City of Peace at the Museon in The Hague, realised in the context of meSch project (Marshall et al., 2016) provides a good example of symbolic objects. The exhibition focused on the impact of the construction of the Atlantic Wall on the city and its citizens and aimed to provide, starting from ten museum objects, three different points of view on the story: Dutch civilians, Dutch civil servants, and the German soldiers. Six objects have been chosen to tell the three stories in Dutch and English: a tea bag (Dutch) and a sugar packet (English) for the civilian, a travel pass (Dutch) and an armband (English) for the civil servant and finally a drinking mug (Dutch) and a dictionary (English) for the German soldier. The objects are selected by visitors at the beginning of the exhibition and, by placing them close to displays across the exhibit, video and audio contents are activated. Albeit the six smart objects are replicas of assets on display in the exhibition, they do not activate interpretive contents about themselves but become metaphor of a particular point of view. They are therefore employed for their evocative power and for their ability to represent and symbolise a character of a story.

The objects are, on the one hand, activators of stories able to contextualise the assets in the exhibit and to convey their intangible value, and on the other, are symbolic of that intangible value: by selecting one of the six objects at the beginning of the exhibition, the visitor acknowledges the meaning they embed.

\subsection{Codified gestures}

The category codified gestures collects those experiences that employ gesture-based interaction to control and activate interpretive contents about the objects on show. We include here projects that ask visitors to perform specific gestures (e.g. raising a hand, stepping, turning their head ...) to access digital contents. Gesture-based interaction is usually allowed by sensors (motion and proximity sensors) or by devices able to read the movement of the full body (e.g. Microsoft Kinect).

A relevant example in the field comes from the project Etruscanning - Digital Encounters with the Regolini-Galassi Tomb (Ray \& Vos, 2013) that allows users to explore and navigate a 3D reconstruction of an Etruscan tomb by using gestures. Explicit and codified movements, captured by sensors, let visitors virtually move within the tomb and experience a digital encounter with a highly realistic VII century B.C. 
Tangible interaction in museums and temporary exhibitions: embedding and embodying the intagible values of cultural heritage.

construction. In this case, the human body becomes the input device and the gestures are the inputs given to the system.

In other projects the body becomes the means to sort artworks or to emulate them: the Gallery One exhibition at the Cleveland Art Museum by Local Project is an example (Alexander et al., 2013). In the Sculpture Lens installation, the facial expressions of visitor are caught and artworks with similar expressions are shown. On the contrary, the installation Strike the pose asks visitors to assume the same pose of sculptures and paintings of the collection with the aim of reaching the best accuracy of the pose.

The three projects described share an instrumental use of the visitors' body since it acts as activators of contents: in the first case it is just a controller of movements in a virtual environment while, in the two others, it acquires the role of sorter and imitator.

The performed gestures are meaningful in respect to a codified list of stored poses but not necessarily add to the comprehension of the artworks or help in conveying the intangible values connected to them.

\subsection{Performing gestures}

The performing gestures category shares with the previous one the use of the body to trigger digital interpretation of artwork but it adds meaning to the gesture itself.

The category collects indeed those experiences that ask visitors to perform meaningful - in respect to the asset on show - gestures to trigger specific effects able to stage the narrative of intangible contents. The gesture itself, beyond its ability to activate digital contents, is imbued with meaning since it becomes representative and symbolic of an intangible value connected to the object on show.

This grouping recalls the classification of technology-enhanced heritage (Lupo et al., 2014) proposed with the European research project Mela* that identified as performing heritage those experiences that call visitors to act and perform gestures able to recall cultural practices as well as to foster the intangible values of cultural assets.

An example that well suits within this category is the Drinking symposium installation at the Allard Pierson Museum of Amsterdam. Born within the European research project MeSch, it is made of a wall projection representing virtual characters taking part to a drinking symposium in the Ancient Greece, a 3D printed replica of a Greek drinking bowl (kylix) and a reproduction of a Greek daybed. Both the kylix and the daybed are embedded with sensors and modify the state of the virtual world when activated. By lifting the kylix, visitors animate a virtual character that lifts his kylix, toasts and drink wine. When the bowl is put down a woman in the virtual scene plays the flute and when a visitor sits on the daybed one of the animated figures shoots a drop of wine from his cup toward a stand in the middle of the room, a game which was popular in ancient Greece (kottabos game).

The gesture of raising and placing back the bowl as well as that of laying on the daybed are therefore inputs for modifying the state on the virtual world but are meaningful in themselves. They make visitors experience actions that have roots in an ancient past and help them to grasp not only the aesthetic quality of the assets on show in the museum but also their intangible value such as their use and relevance within a ritual. 


\section{Emerging tangible-interaction oriented design strategies enabling the experience of intangible values of $\mathrm{CH}$}

The four categories of tangible interaction described in the previous chapter highlight different ways of providing interpretive digital contents during cultural experiences. They share the will to involve actively visitors in bodily experiences, asking them to touch and manipulate objects and to perform actions with the hands or with the full body.

Despite this common ground, we can recognize differences in the strategies employed. The first two categories collect experiences that attach great importance to the physical manipulation or instrumental use of objects, being them original assets, replicas or symbolic objects. The paradigm of interaction they refer to is therefore that of embedded interaction. The last two groups of projects shift instead the focus on performed gestures as triggers of interpretive contents, referring therefore to embodied interaction.

Dissimilarities exist also within these two homogeneous groups. Analysing each category in detail we can recognise how the first and the third category - smart replicas/originals (i), codified gestures (iii) employ tangible interaction as a simple trigger to activate interpretive contents. Beyond the added value of handling original objects (i) or to use the body instead of input devices (iii) the act of touching or performing gestures does not necessarily add to the communication and comprehension of the intangible values connected to the assets on show. The design action simply attaches to tangible interaction the role of trigger: the meaning is entrusted to the interpretive contents activated by the interaction, being it embedded or embodied interaction.

The strategy is different for the second and fourth categories - symbolic objects (ii), performing gestures (iv) - which attach meaning (related to the intangible values of the objects on show) to the object to be manipulated and to the gestures. The projects encompassed in these groupings employ tangible interaction not only to activate contents related to the intangible values, but also embed (ii) and embody (iv) meaning respectively in the sensorised object and in the gesture. The design action attaches meaning and includes the intangible values to be communicated directly into the object and in the gesture, and therefore acts as a translator of meaning.

We can therefore highlight two design strategies of employment of tangible interaction for enabling the experience the intangible values of Cultural Heritage: embedding meaning and embodying meaning.

The first strategy, embedding meaning, integrates explicitly the meaning into sensorised objects and focuses on their physicality. The object itself, for its significance in relation to the context in which it is employed, embeds directly and overtly meaning in respect to intangible values. Beyond its interactivity, it becomes a representative object, able to communicate in itself the intangible values it embeds.

The second strategy, embodying meaning, integrates implicitly the meaning in the gesture, focusing therefore on the act rather than on the object. The performed gesture, for its relevance to intangible values connected to the cultural assets, acquires meaning in itself. By performing a gesture, such as miming a ritual gesture in the Drinking symposium, visitors implicitly understand an intangible value of an asset, the value of use and its symbolism in this specific case. 


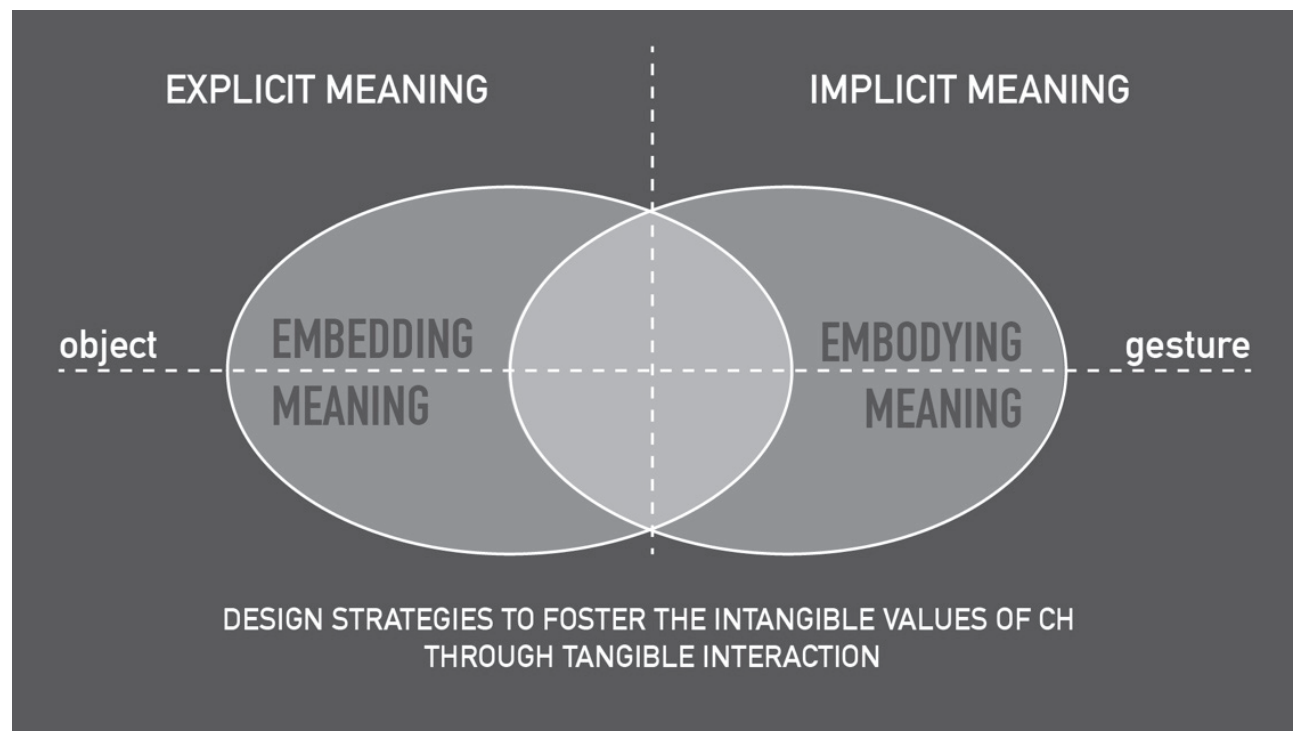

Fig. 1 Schema summarising the two design strategies to foster knowledge on the intangible values of CH through tangible interaction

The two strategies here highlighted are necessarily permeable and can coexist within the same experience: the Drinking symposium cited above is a clear example. The focus is indeed on the gesture of raising the bowl and sitting on the daybed but the two objects themselves embed meaning, being them replicas of assets exposed in the museum. A very different result would be obtained changing them with a contemporary glass and bench.

\section{Conclusions}

In this paper tangible interaction has been analysed from a peculiar perspective, that is, from the point of view of its ability to enable the experience of intangible values in cultural heritage. Starting from a collection of case studies, different categories of tangible interaction have been identified and then discussed in relation to their ability to foster intangible values. In addition, two design strategies that allow the achievement of this goal have been highlighted. These strategies, that can be referred to as embedding meaning and embodying meaning, differ for the way the meaning related to an intangible value is conveyed (i.e. emphasis on the object or on the gesture, explicit or implicit integration of meaning). Through this paper we have tried to provide a theoretical contribution to the understanding of the potentials of tangible interaction in enabling certain kinds of experience in cultural heritage. In doing so, we have tried to shift the focus from the interaction through the technology in itself to the results in terms of the experience enabled by certain design choices (Hassenzahl et al., 2013).

The theoretical contribution provided by this paper, beyond providing a conceptualization of a specific aspect of the use of tangible interaction, could be useful for designers and cultural heritage professionals. In particular, it can support them in the choice of certain design solutions according to the effects they want to obtain or the type of intangible value they want to communicate.

However, it has to be acknowledged that this work represents just a preliminary theoretical contribution to the field. Indeed, so far, the research in the field of tangible interaction in cultural heritage has been mainly characterized by the creation and evaluation of practical projects, while not many theoretical contributions have been provided. This makes the field very new, complex, and open to different kinds of 
explorations. Therefore, this paper is presented as a starting point for a theoretical reflection that will possibly be developed further in future works.

\section{References}

ALEXANDER, J., BARTON, J., GOESER, C. (2013) "Transforming the Art Museum Experience: Gallery One". In Proctor, N. Cherry, R., Museums and the Web 2013, Silver Spring, MD: Museums and the Web.

BALZOLA, A., ROSA, P., (2011). L'arte fuori di sé. Un manifesto per l'età post-tecnologica. Milano: Feltrinelli.

BANNON, L., BENFORD, S., BOWERS, J., HEATH, C. (2005). "Hybrid Design Creates Innovative Museum Experiences" in COMMUNICATIONS. ACM. 48, no. 3: 62-65.

CHATterJeE, H., MACDONALD, S., PRYTHERCH, D., NOBLE, G. (2008) Touch in Museums: Policy and Practice in Object Handling. Oxford: Berg.

CIOLFI, L.; BANNON, L. (2003) "Learning from museum visits: Shaping design sensitivities". In: Proceedings of HCI International. p. 63-67

CIOLFI, L., BANNON, L. (2005). "Space, Place and the Design of Technologically-Enhanced Physical Environments”. In Turner, P., Davenport, E., Spaces, Spatiality and Technology (pp. 217-232). Springer Netherlands.

CIOLFI, L., AVRAM, G., MAYE, L., DULAKE, N., MARSHALL, M.T., VAN DIJK, D. AND MCDERMOTT, F. (2016), "Articulating Co-Design in Museums: Reflection on Two Participatory Processes", in Proceedings of CSCW 2016, New York: ACM, 13-25

COUTRIX, C., NIGAY, L. (2006) "Mixed Reality: A Model of Mixed Interaction". In: Proceedings of AVI 2006, Venezia, Italy, 23-26 May 2006, pp. 43-50. ACM Press, New York.

DOURISH, P. (2001). Where the Action Is: The Foundations of Embodied Interaction. Cambridge, Mass.: The MIT Press.

DUDLEY, S. (Ed.). (2009) Museum Materialities: Objects, Engagements, Interpretations. London; New York: Routledge.

FERRIS, K., BANNON, L., CIOLFI, L., GALLAGHER, P., HALL, T., LENNON, M. (2004). "Shaping Experiences in the Hunt Museum". In: DIS '04 Proceedings of the 5th conference on Designing interactive systems: processes, practices, methods, and techniques. ACM, 205-214.

FRASER, M., STANTON, D., NG, K. H., BENFORD, S., O'MALLEY, C., BOWERS, J., TAXÉN, G., FERRIS, K., AND HINDMARSH, J. (2003). "Assembling history: achieving coherent experiences with diverse technologies". In: Proceedings of the Eight European Conference on Computer-Supported Cooperative Work, 14-18 September 2003, Helsinki, FINLAND:A CM, 179-198.

HALL, T., ET AL. (2001). "The visitor as virtual archaeologist: explorations in mixed reality technology to enhance educational and social interaction in the museum" in Proceedings of the 2001 conference on Virtual reality, archaeology, and cultural heritage, New York, USA: ACM

HASSENZAHL, M., ET AL. (2013). Designing Moments of Meaning and Pleasure. Experience Design and Happiness. International Journal of Design, 7(3), 21-31.

HORNECKER, E., \& BUUR, J. (2006). "Getting a grip on tangible interaction: a framework on physical space and social interaction" in Proceedings of CHI 2006, 437-446. ACM Press.

HORNECKER, E. Tangible Interaction <https://www.interaction-design.org/literature/book/the-glossary-of-humancomputer-interaction/tangible-interaction $>$ [Consulted: $12^{\text {th }}$ May 2016]

HSIEH, C.K., ET AL. (2010) "Yongzheng emperor's interactive tabletop: seamless multimedia system in a museum context" in Del Bimbo, A. Chang, S., Smeulders, A., ACM Multimedia, ACM, pp. 1453-1456

ISHII, H., ULLMER, B. (1997). "Tangible bits: towards seamless interfaces between people, bits and atoms" in CHICONFERENCE ACM Press. 234-241.

LUPO, E., ET AL. (2014). "Migrations and multiculturalism: a design approach for cultural institutions" in Innocenti, P. Migrating Heritage: Experiences of Cultural Networks and Cultural Dialogue in Europe. London: Ashgate. 6577. 
Tangible interaction in museums and temporary exhibitions: embedding and embodying the intagible values of cultural heritage.

MARSHALL, P, HORNECKER, E, (2013) "Theories of Embodiment in HCI". In ”, in Price, S., Jewitt, C., Brown, B The Sage Handbook of Digital Technology Research. Sage Publications

MARSHALL, M. T., ET AL. (2016). "Using Tangible Smart Replicas as Controls for an Interactive Museum Exhibition" in Proceedings of the TEI '16: Tenth International Conference on Tangible, Embedded, and Embodied Interaction. ACM press, 159-167.

MILGRAM, P., \& KISHINO, F. (1994). A taxonomy of mixed reality visual displays. IEICE Transactions on Information Systems, 12, 1321-1329.

PETRELLI, D., ET AL. (2013). "Integrating Material and Digital: A New Way for Cultural Heritage". In Interactions, 20(4), 58-63.

PETRELLI, D.; NOT, D., DAMALA A., VAN DIJK, D., LECHNER, M.,(2014) "meSch - Material Encounters with Digital Cultural Heritage" in Digital Heritage. Progress in Cultural Heritage: Documentation, Preservation, and Protection, Springer International Publishing, 536-545

PUTNAM, J. (2009). Museum as medium. London: Thames \& Hudson.

PYE, E. (2007) The Power of Touch: Handling Objects in Museum and Heritage Contexts. Walnut Creek, Calif: Left Coast Press.

RAY, C., VOS, J. (2013). Etruscanning - Digital Encounters with the Regolini Galassi Tomb.

RAWAT, T. J. (2005). "Wonder Objects - Magic and Interactive Storytelling" In COGNITIVE SCIENCE RESEARCH PAPER- UNIVERSITY OF SUSSEX CSRP. no. 577: 91-96.

SHAER, O., HORNECKER, E. (2010), "Tangible User Interfaces: Past, Present, and Future Directions", in Foundations and Trends in Human-Computer Interaction: Vol. 3: No. 1-2, pp 4-137

STEVENS, R. (2004) "Leaving a Trace: Supporting museum visitor interaction and interpretation with digital media annotation systems.” Technical Report. Cognitive Studies in Education, University of Washington.

TAYLOR, R., ET AL. (2015). "Making Magic: Designing for Open Interactions in Museum Settings" in Proceedings of the 2015 ACM SIGCHI Conference on Creativity and Cognition (C\&C '15). ACM, New York, NY, USA, 313-322.

VLAHAKIS, V., ET AL. (2002). "Archeoguide: an augmented reality guide for archaeological sites" in IEEE Computer Graphics and Applications, 22(5), 52-60.

VOM LEHN, D., HEATH C. (2003) Displacing the object: Mobile technologies and interpretive resources. In Proceedings ICHIM International Cultural Heritage Informatics Meeting.

WELLNER, P., MACKAY, W., GOLD, R. (1993) "Computer-augmented environments. Back to the real world" in Communications of the ACM, vol. 36, no. 7, pp. 24-26. 